\title{
Too many 'false dichotomies'? Investigating the division between ageing and disability in social care services in Ireland: A study with statutory and non- statutory organisations
}

\author{
Ann Leahy \\ Irish Research Council Scholar and John and Pat Hume Scholar, Department of Sociology, Auxilia Building, Maynooth University, Kildare, Ireland
}

\section{A R T I C L E I N F O}

\section{Keywords:}

Public-policy

Ageing

Disability

Biopsychosocial

Lifecourse

Ireland

\begin{abstract}
A B S T R A C T
Initiatives that bridge the fields of ageing and disability are considered critical internationally but to be limited in practice. Taking Ireland as a case, and focusing on social care, this article reports on a study investigating the separate organization of older people's and disability services as perceived by those working in policy-making, service provision and advocacy. In Ireland, as in many countries, social care is administered separately for disabled people and older people. Perceptions of those working in social care are thought to play a role in successful boundary-crossing initiatives. This study suggests that while participants often perceived the administrative and funding boundary between the fields of ageing and disability as illogical, inflexible, and not delivering person-centred care or support, the divide between the two sectors is underpinned by conceptual issues, including the lack of a concept of disability with ageing. The article argues that ways are needed of articulating what it is to experience disability in older age that are shared between older people's and disability sectors. It discusses bio-psychosocial models of disability as a means of doing so, one that avoids a return to an equation between older age and impairment, disability or decline. It concludes that more interrogation is needed of the separate philosophical underpinnings of disability and older people's sectors, argues for greater linkages between the two fields and for more exploration of social constructions of the experience of disability in later life.
\end{abstract}

\section{Introduction}

Older people tend not to be considered 'disabled' in the same way as children, young people or adults might be (Priestley, 2002, 2006). This is reflected in many countries in two distinct research and public policy traditions, one on ageing using a medical model, and one on disability focusing on a social care model that challenges medical approaches from a social advocacy perspective (Monahan \& Wolf, 2014). Experiencing functional limitations in older age is considered normative something that fuels lowered expectations for independence and selfdirected care - while insufficient attention is paid to how social constructions of disability shape the ageing process (Kelley-Moore, 2010).

The greying of the population due to greater longevity is well-recognised, and it is also clear that large numbers of people are now ageing with early-onset disability (Freedman, 2014; LaPlante, 2014). The World Report on Disability estimates that $15.6 \%$ of adults experience disability (World Health Organization and The World Bank, 2011, based on the World Health Survey). The rate rises to between $38.1 \%$ and $46.1 \%$ for those aged over 60 . But at population level the interrelationship between ageing and disability is complex (Lloyd, 2012). A focus on social structural influences over the life course problematizes the view that physiological ageing is the only explanatory factor for disability with age (Kelley-Moore, 2010). For example, less socially integrated older people are more likely to perceive themselves as disabled independent of functional status (Kelley-Moore, Schumacher, Kahana, \& Kahana, 2006). The social construction of disability has been highlighted by a large-scale study from the U.S., suggesting that disabled older people are more likely to be female, older, non-White, have less than a high school degree and to live in poverty, compared with non-disabled older people (Henning-Smith, 2016).

The separate organization of public policies on disability and ageing has produced age-based theories and conceptual frameworks, bifurcated scientific knowledge bases, parallel fields of professional practice and system-specific ideologies, vocabularies and cultures of service delivery (Putnam, 2014:S51). Complexity and confusion are associated with these separate administrative categories (Priestley \& Rabiee, 2001; Putnam, 2007). Bridges across the two fields in research, policy, and practice are considered critical internationally to address both demographic ageing and increased longevity of lifelong disabled people (Bickenbach et al., 2012). But these are also considered to be limited in

E-mail address: ann.leahy.2014@mumail.ie. 
practice, with significant barriers to communication and informationsharing (Salvador-Carulla et al., 2009). Closer links between scholarship in gerontology and disability studies have also been called for (see Grenier, Griffin, \& McGrath, 2016; Kennedy, 2000; McGrath, Rudman, Trentham, Polgar, \& Spafford, 2017; Naidoo, Putnam, \& Spindel, 2012; Oldman, 2002; Putnam, 2007). Kennedy (2000) highlights policy as an area where scholars on disability and ageing could collaborate on issues of vital interest to younger and older disabled people.

Within representative groups of older people or disabled people, common concerns can be identified (such as in housing, transport, income, choice and dignity), but there is a 'strong counter-tendency' within the two movements, with older people advocating for 'active ageing' in response to the imagery of dependency, while disability activism prioritises issues such as employment or parenting (Priestley, 2002:368).

This paper examines the case of the Irish public policy approach to social care provision.

As in many other countries, Ireland's provision is organised into separate categories with separate funding arrangements for disability and ageing with the boundary defined by reference to age 65 . Ireland's provision of social care may be about to undergo fundamental change with recently announced moves towards a widespread personalised approach, mirroring developments elsewhere. ${ }^{1}$ In Ireland the proposed personalised approach is described as giving 'people with disabilities more control in accessing health-funded personal social services, giving them greater independence and choice in accessing services which best meet their individual needs' (Department of Health, 2016:2).

The study reported in this article forms part of a larger exploration of the experience of physical/sensory disability in older age. This article concerns one part of that study - that conducted with people working in policy-making, service provision and advocacy on disability and on ageing. I discuss key findings relating to how participants understood disability in older age, with most participants considering older people with impairments as just 'elderly' or 'older,' and how this was informed by the institutional or organisational and funding boundary, which, thus, helped to construct how participants understood what it is to be disabled and older and what types of services were appropriate for the two groups (that is, disabled people and older people). Thus, understandings of policy-makers and practitioners were found to be embedded within existing segmented policies. Positive ageing discourses are influential amongst some participants and are associated with distancing from ideas of impairment, disability or decline, which, paradoxically, is attempted without a language in which to consider people who do experience disability with ageing.

I go on to argue that we need ways of discussing disability in older age that do not simply equate it with impairment or, indeed, with ageing. I suggest that a relational or biopsychosocial model of disability may represent a way to recognise both 'impairment' (in the body) and 'disability' (occurring in the interaction between the bodily and the contextual), and argue for this approach to understandings of disability in later-life. This is for its possible efficacy as an analytical construct and as a political argument. I also argue for more exploration of social constructions of the experience of disability in older age and for more linkages in research, policy-making and activism between ageing and disability fields. This, I suggest, is needed to facilitate interrogation of their separate philosophical underpinnings as a necessary part of any integration of approaches between older people's and disability programmes.

\footnotetext{
${ }^{1}$ Countries tend to use a range of different personalised models. The central idea is to enable individuals to have increased levels of choice and control (Anand, Davidson, Macdonald, \& Kelly, 2012). In the U.K. a personal budget can be managed by the local authority or by a third party that commissions services for users, or it can be given to users or their carers as a direct payment (National Audit Office, 2016:5). Disabled activists are especially associated with campaigns for direct payments (Glasby, 2011).
}

\section{Some definitions}

The meaning of 'disability' is contentious (O'Donnell, 2007; Townsend, 1981) and all terms and definitions are imperfect (Graby, 2015). Clarifying terms involves theory, since the most fundamental issue in the sociology of disability is conceptual (Abberley, 1998:79). Space does not permit a detailed exploration of definitional issues here, but I argue that 'disability' remains a 'necessary concept' in political terms (De Schauwer, Van de Putte, Claes, Verstichele, \& Davies, 2016:1099).

I use the phrase 'disabled people' as it is used amongst scholars/ activists in the U.K., who use it to shift the focus from the individual to society (Morris, 2001; Priestley, 2003a). I understand disability in a way that is consistent with the United Nations (U.N.) Convention on the Rights of Persons with Disabilities (United Nations General Assembly, 2006), where disabled persons are defined as:

... those who have long-term physical, mental, intellectual or sensory impairments which in interaction with various barriers may hinder their full and effective participation in society on an equal basis with others (Article 1).

This definition is linked to the World Health Organization (WHO) 'family of international classifications' that assumes that the experience of disability is a universal human experience (World Health Organization, 2002:3; World Health Organization and The World Bank, 2011). The model is a biopsychosocial one in which disability is said to arise from the interaction of individual conditions with contextual factors, which are personal and environmental. Environmental factors include the natural and built environment, support and relationships, attitudes and services, systems, and policies (World Health Organization and the World Bank, 2011:5). Thus 'disability' is relational - it includes, but is broader than, 'impairment', which is defined as problems in body function or alterations in body structure.

The terms 'disability with ageing' or 'ageing into disability' are used of people who live relatively disability free until reaching mid-life or late-life, while the term 'ageing with disability' is used of people who are either born with some form of impairment, or first experience it in their childhood, young adult or adult years (Verbrugge \& Yang, 2002).

\section{Policy background}

\section{Public policy - international trends}

Concerns about the public policy implications of demographic ageing have given rise to surprisingly little linkage with parallel debates over disability rights and policies within governments, public services and movements of older or disabled people (Priestley, 2002).

But a growing literature from a number of countries (including Australia, Canada, France, Sweden, Switzerland, the United States and the U.K.) suggests that separate policy and practice approaches are associated with issues and anomalies (see Bigby, 2008; Le Bihan, 2016; Bishop \& Hobson, 2015; Cooper \& Bigby, 2014; Jönson \& Larsson, 2009; Priestley, 2002, 2003b; Priestley \& Rabiee, 2001; Putnam, 2002, 2007; Rickli, 2016). For example, a tendency is identified in disability policies and in activism to overlook older people, to define older disabled people as 'elderly' rather than 'disabled' and to provide them with services of lower quality than those given to their younger peers (Jönson \& Larsson, 2009). People experiencing disability in older age were offered a narrow range of services (with few receiving services specific to rehabilitation and social support) in the United Kingdom (U.K.) (Bowling, Farquhar, \& Grundy, 2008), and were less likely than younger disabled people to be offered 'rehabilitation training and equipment' in the U.S. (Kane \& Kane, 2005: 52).

Some specific issues have been identified relative to those ageing with disability. One concerns the extent to which they can access specialised aged-services and the risk that their experience of premature 
ageing may be overlooked (Bigby, 2008; LaPlante, 2014). Another is that they may be marginalised in public policy on ageing by the emphasis on active participation (Raymond, Grenier, \& Hanley, 2014).

Given their separate political and policy pasts, building and sustaining bridges between the two fields of ageing and disability is not a simple task (Putnam, 2007). There has been limited scientific investigation of perceptions and beliefs of administrative and practice professionals, which are thought to play a key role in successful boundary-crossing initiatives between disability and older people's programmes in home/community services (Putnam, 2011). In one study, professional investment in age-segmented policies and programmes operated as a barrier to working with different user groups (Putnam, 2011:338). That study's participants emphasised life stages, sometimes reproducing stereotypical notions about what services older people might need (bingo and cards in one case). Organisational and professional training and support was identified as necessary to facilitate working with unfamiliar client groups. That study raised the question of whether the 'policy regulations drive professional perceptions or vice versa' and indicates challenges of implementing change (Putnam, 2011:338).

Collaboration and training helped to manage competing logics and philosophies held by directors and staff of amalgamated disability and ageing organisations in the U.S. (Keefe, 2014). In the U.K., Rabiee, Baxter, and Glendinning (2016) found that new commissioning and brokerage arrangements have potential to give older people using managed personal budgets greater choice and control over their support, but inadequate training for practitioners limited opportunities for them to exercise choice, as did resource constraints.

But if artificial distinctions based on chronological age risk overlooking service needs and desires for personal autonomy that bridge age groups (Kennedy \& Minkler, 1999), applying approaches associated with disability activism to the social care of older people without sufficient scrutiny of all the issues involved can also produce mixed or disappointing results.

The emergence of schemes offering greater choice and control, known as individualisation or personalisation, in social care in the U.K. provides a window into some of the challenges associated with the latter. Disabled activists (such as Morris, 1993, 2006; Oliver, 1990) are associated with these changes; something that divided a range of stakeholders from the outset (Glasby, 2011:7). Older people are by far the largest group of social care users (Woolham, Daly, Sparks, Ritters, \& Steils, 2017), and debate has focused on how well the personalisation agenda works for them (see for example, Glendinning et al., 2008; Lloyd, 2010; Glasby, 2011; Woolham et al., 2017; Rabiee et al., 2016). For example, Lloyd (2010) argues that issues of independence and choice are not the only ones relevant to care of older people, particularly ones with complex and changeable needs.

Recent studies query how far the benefits of personalisation are in fact available to the vast majority of older people (Rabiee et al., 2016; Slasberg \& Beresford, 2016). Despite a positive narrative about the changes, it is argued that a two-tier system is operating in England where older service users have experienced little change (Slasberg \& Beresford, 2016). However, potential to promote personalisation amongst older people is also identified (Rabiee et al., 2016).

But the broader context is also relevant. Greater 'individualisation' has been created through a rhetoric of 'personalised care' and 'consumer choice' across North America, Europe and East Asia (Higgs \& Gilleard, 2015:38). Concepts advocated for by disability activists were adopted in response to population ageing to limit state involvement (Lloyd, 2010), have been reconceived in consumerist terms (Riddell et al., 2006: Beresford, 2008) and implemented (in the U.K. at any rate) simultaneously with reductions in funding (Slasberg \& Beresford, 2016).

Furthermore, older people are not the only groups to experience problems with personalisation, or with the way it is implemented (see Duffy, 2012; Glasby \& Littlechild, 2016; Graham, 2015). From the perspective of disabled activist/scholar Gerry Zarb (2013), the personalisation agenda does not play the role anticipated in securing equality and full citizenship. He queries if greater alliances with other user groups would have had better outcomes and suggests that they may still be needed.

In the U.K., Beresford (2008) called for those concerned with social care to subject its underpinning ideas to rigorous review; and in the U.S. Putnam (2014) has suggested that bridging research should be a high priority for practitioners, policy makers and scholars working in the fields of ageing and disability. The above illustrates the need to interrogate assumptions that underpin provision of social care to disabled people, including older disabled people, which is what this study sought to do in the Irish context.

\section{Public policy - Ireland}

In terms of social policy, Ireland is often seen as similar to the U.K. and classified as a liberal regime (Walker, 2015). The Irish care regime can also be characterised as equating to the family-care model identified by Anttonen and Sipila (1996) with elements of the means-tested model, where informal family-care is significant (Timonen, Convery, \& Cahill, 2006). Social care in the community is characterised as 'patchy and fragmented' (Connolly, 2015: 28). A key weakness is absence of statutory underpinning for homecare (O'Shea, Cahill, \& Pierce, 2015) while access to institutional care is facilitated through a statutory scheme involving co-payment between the state and the service-user. Over $60 \%$ of the budget for the provision of services for older people goes towards support for the approximately $4 \%$ of the over 65 population who are supported by the state to live in long-term residential care (Department of Health, 2015).

There are separate national policies on ageing and on disability. The only reference to disability within the goals and objectives of the National Positive Ageing strategy (published in 2013), is to its prevention (objective 2.1). This is despite the fact that some iterations of national disability policy suggest that older people's services are responsible for older life-long disabled people (see Expert Reference Group on Disability Policy, 2010; Working Group Report, 2012).

Disability programmes and ageing programmes are distinct, and different service care models apply. Traditionally, client categories were defined by reference to chronological age (over 65) or disability type, including physical/sensory disability (Conroy \& Mangan, 2006). Separate ageing and disability sections operate with separate budgets within the Department of Health and the Health Service Executive, the body responsible for the national health service, where they both come within the Social Care Directorate. Separate funding arrangements within Irish health and social care are considered to militate against boundary-crossing, and to create a variety of difficult situations for some groups of older disabled people, such as those with early onset dementia (Conroy \& Mangan, 2006). For those ageing with lifelong disability, the policy framework has received little attention and is not well developed (Anand et al., 2012), something that mirrors the position in other countries (see Bigby, 2002; Raymond et al., 2014).

There are also differences of conceptualization. Disability programmes 'typically incorporate concepts of independence, autonomy, self-direction and empowerment', while ageing programmes tend to follow the medical model with less choice or autonomy available relative to the type and timing of services received (Murphy, O'Shea, Cooney, \& Casey, 2007:46). For example, in home care provision for older people, there is no explicit emphasis on social/companionship, while services for (younger) disabled people may include leisure activities or quality time (Timonen, Doyle, \& Prendergast, 2006:205).

Two separate - and potentially overlapping - initiatives on social care are under way during 2017 from the disability and older people's sections of the Department of Health, respectively. Mirroring developments that have already taken place in other countries (see Anand et al., 2012), the first involves moves towards a widespread personalised 
approach designed to facilitate increased levels of choice and control for 'people with disabilities' (Department of Health, 2016). Simultaneously, the second involves a consultation process relative to homecare - concerning proposals for a new statutory scheme and system of regulation (Department of Health, 2017). Advocacy groups have responded in the context of the latter by pointing out the need to address homecare delivery across the lifecourse (Active Ageing Partnership et al., 2017).

\section{Methods}

The study explored how those working in the two fields of ageing and disability perceived the operation of the administrative and funding boundary related to the chronological age of 65 . In addition, the study also sought to establish facts in relation to some practice issues. This article mainly addresses the findings related to the first of these.

The approach was qualitative, and intended to explore the meaning participants brought to the issues (Denzin \& Lincoln, 2000:3). The study involved a grounded theory method (Charmaz, 2005; Charmaz, 2014; Strauss \& Corbin, 1998) and took a constructivist approach that assumes that researchers are engaged in an interpretive portrayal of the studied world (Charmaz, 2005, 2014). This involves 'flexible analytic guidelines' for data collection, stages of analysis and conceptual development (Charmaz 2005:507; 2014).

The process did not go so far as to constitute grounded theory - as sampling was purposeful not theoretical - but followed the five steps outlined by Charmaz (2014:15) as constituting a grounded theory study: namely, data collection and analysis conducted simultaneously and iteratively, analysis of actions and processes, comparative methods, developing conceptual categories from the data and inducting abstract categories through systematic analysis. This meant that transcripts were initially open-coded and similarities and differences noted between the various cases. I compared cases and revised codes and engaged in focused recoding. Constant comparison highlighted differences as well as similarities across cases. Finally, I identified categories and the relationships between categories. A software programme was used to organise the data.

Interviews took place between June 2015 and May 2016 with 16 participants. I recruited participants who worked in ageing or disability in three areas: (1) policy-making or advising, (2) management/administration of services supporting people to live in the community, and (3) advocacy or related activities within NGOs. A representative was also sought from an NGO whose remit crossed over the two sectors. Most participants worked for statutory or non-profit organisations with a national remit. One worked for a private home-care provider. Initial sampling was purposeful like most sampling in qualitative research (Maxwell, 2008). A snowball sampling process followed where informants suggested others. See Table 1.

A semi-structured interview approach facilitated asking similar questions across interviews and comparison across cases, and also allowed flexibility as to how topics were covered (Bernard \& Ryan, 2010).

Ethical approval was obtained from the Maynooth University

Table 1

Categories from which Participants were drawn.

\begin{tabular}{lll}
\hline Area of experience & Disability & Ageing \\
\hline & $\mathrm{N}$ & $\mathrm{N}$ \\
\hline Policy-making or advising on policy & 2 & 2 \\
Service provision focusing on social care & 3 & 3 \\
NGOs involved in representation/advocacy and related & 3 & 2 \\
$\quad$ programme delivery & &
\end{tabular}

NGO involved in advocacy whose remit crossed over the two areas of disability and ageing: $\mathrm{N}=1$
Research Ethics Committee. Informed consent was obtained in writing from interviewees.

\section{Findings}

Three categories identified in the data concerned (1) how disability in older age was understood, (2) how services were conceived of for the two groups, and (3) practice issues. The first category 'how disability in older age was understood' was the core category. How participants understood 'disability' was informed by the segmented institutional arrangements and funding boundary between the two services, and it in turn reinforced or legitimated issues like distinct types of supports and services thought appropriate or inappropriate to the two groups. I concentrate here on findings related to the first two categories, but also address participants' perceptions about how well the separation between the two services was working overall, and whether they perceived that greater integration was desirable.

\section{How disability in older age is understood}

Participants often had no concept of disability with ageing, and identified older people acquiring impairments as just 'elderly' or 'older people'. This meant that for participants who rejected the conflation of the concept of older age and disability (or related concepts) there was no language with which to talk about older people who did experience onset of impairments or disability. Those participants who did consider that people first experiencing impairment in later life could be encompassed within the category 'disabled' tended to come from the nonprofit disability sector and invoked a biopsychosocial model of disability. A key finding was that understandings of impairment or disability in older age (or the lack of them) were informed by and constructed in terms of the segmented institutional arrangements and funding boundary between the two services, and could in turn influence thinking about distinct types of supports and services being appropriate to the two groups. The two were mutually reinforcing.

\section{No concept of disability in older age?}

People in both ageing and disability fields felt that there was no concept of 'disabled older person' except for someone who was ageing with lifelong disability. People who experienced impairments with ageing were considered not 'disabled' but 'old(er)' or 'elderly'. For example, a manager of a medical day centre for older people considered that her client group often experienced disability, by which she meant not regaining full functioning, but were thought of as 'older people.'

A senior person from an age-sector NGO said that when she thought of an older 'disabled' person it was someone who experienced lifelong disability. She described how in the past ageing and disability were considered synonymous - 'maybe old equalled disabled' - and how ageorganisations resisted this conflation. A similar understanding was articulated by a policy-maker/advisor on ageing who also took issue with the fact that older age was often thought to be synonymous with disability:

I think most people who haven't thought about this think of ... all older people as disabled in some form. They probably wouldn't use the word ... I think there's a real problem in that an awful lot of people assume all older people are disabled, which they are not (Policy-maker/advisor, ageing 1).

Another staff-member of an age sector NGO described how the focus in her organization is on active ageing and 'continuous engagement', which is understood to mean being able-bodied. The concept of the 'third age' is used, but the 'fourth age' is never mentioned. Terms like 'disabled', 'frail' or 'impaired' are not used. However, she also reflected during the interview how some of the work involves an implicit understanding that people are at risk of isolation due to disability: 
So while the word 'disabled' isn't used around that table, I imagine implicit in that [is that] people are being befriended at home because they have a disability and can't get out (staff-member, NGOageing 2).

These findings are consistent with findings from other studies of a tendency to define older disabled people as 'elderly' rather than 'disabled' (Jönson \& Larsson, 2009). Those ageing with disability are considered 'disabled' while people who experience disability for the first time in later life are not. Thus the findings reflect an understanding of disability as generationally situated ${ }^{2}$ (Priestley, 2006) with age, impairment and disability conflated in later life (Grenier et al., 2016).

This represented a paradox for some participants. They contend with a generalised conflation of the concept of older age and disability, frailty or functional restrictions, and seek to distinguish the majority of older people from this image. Yet they also do not have a language with which to talk about older people who do experience onset of impairments or disability, other than it being implicit in some understandings of what it is to be older and marginalised or isolated. There is a sense of concepts like successful ageing, third age or active ageing 'obliterating' or 'cancelling' the so-called fourth age (Timonen, 2016:81) in rhetorical terms. It also reflects the extent to which these discourses have become associated with the ideal of being able-bodied throughout the lifecourse (Gibbons, 2016).

\section{Disability in older age equated with decline?}

There was a tendency on the part of some of those working on disability to explain the distinction between disability services and older people's services on the basis that what people experience in older age is 'decline,' closely linked to end of life. This was articulated by some personnel within the statutory sector and was associated with the view that older people's services needed to be more medicalized and have less focus on social or community participation than disability services. For example, 'decline' was used to explain the division between older people's and disability services:

But the disability directorate doesn't deal with people who are gradually crumbling with old age ... the declining physical and other capacities of old age was for older person's services (Policymaker/advisor, disability 1).

Conflating disability in older age with decline and end of life, in the way that a small number of participants working on the disability side did, conjures an image of 'a dark period of inevitable decline,' and fails to take account of a lifecourse perspective on ageing, which, contrariwise, recognises how variable (across individuals, groups, nations) and contingent ageing is (on health, wealth, relationships, policies etc.) (Dannefer \& Settersten, 2010:4).

Assuming that disabled older people are experiencing 'decline' and that consequently it is appropriate for services not to focus on social and community participation, also risks overlooking the ongoing tenacity and efforts of disabled, frail and/or ill older people to continue to engage with life as evidenced in a series of studies (for example, Grenier, 2005; Lloyd, Calnan, Cameron, Seymour, \& Smith, 2014; Murphy et al., 2007; Nicholson, Meyer, Flatley, \& Holman, 2013; Warmoth et al., 2016). For example, people aged 86-102, categorised as frail, demonstrated engagement in 'extraordinary work' involving creativity and capacity to overcome or find others to overcome physical, emotional or social vulnerabilities (Nicholson et al., 2013:1179).

However, other participants working on the disability side saw a more nuanced picture. One staff-member of a disability NGO identified the lack of and inflexibility of services to support older people to live at home as a disability and a human rights issue. Another person, also

\footnotetext{
${ }^{2}$ By which Priestley (2006) means that the same impairment characteristics regarded as aberrant in younger bodies are often viewed as 'normal' in ageing bodies.
}

working in disability, described too many 'false dichotomies' operating in thinking about ageing and disability. She attributed the distancing of the two sectors to prejudice and discrimination, along with 'bureaucratic' issues and competition for funding. Asked if older people were considered 'disabled' in the same way as younger people, she said:

I feel that these barriers about who is a person with a disability and who is an older person are artificially placed there for perhaps bureaucratic reasons ... [or] the presence of prejudice and of discrimination ... All that is complete nonsense if you take a social model approach ${ }^{3}$ and look at the relationship with the environment. ... We are all going to become more impaired than we are now. Whether we are very impaired to start off with or not very impaired to start off with we will become more impaired (Policy-maker/advisor, disability 2).

A similar view was articulated by several participants working in disability who took a lifecourse understanding of disability, capable of encompassing both those ageing with disability and those experiencing disability with ageing. Some of them were working to include people first experiencing disability in later life in the work of their organisations, although that work principally targeted younger disabled people. Several of these participants referred to their understanding of disability by reference to the U.N. Convention on the Rights of Persons with Disabilities (United Nations General Assembly, 2006).

\section{Funding boundary constructing how disability in older age is understood}

Participants demonstrated that the funding boundary at age 65 (itself, of course, an arbitrary age but one reinforced by administrative systems like pensions) influences how they thought about both what it is to be disabled and older and also about what supports and services should be available to older disabled people.

Repeatedly, how disability is understood in older age was linked to how services for this group are organised or conceived of. For example, asked how disability with ageing was understood, a manager of services to older people working within the national health service said, 'if you acquire a disability as an older person, the care and support is based around literally the maintenance of immediate activity to daily living'.

Also responding to this question by reference to how the services are organised, a participant working in a disability organization said:

... if I was to think about it in very simple terms it's the very passive person who's probably got a limited range of services, just left there you know with nobody...not being able to advocate for themselves or for others. It's very much ... that medicalised notion (NGO staffmember, disability 1).

But she was aware of holding contradictory viewpoints, and she went on convey another view:

If you were to ask me to put my social policy hat on then it would be something that's quite different, because I think as we all are growing older we all acquire some form of disability and there are so many older people who are living well with disability of whatever shape or form it is (staff-member, NGO-disability 1 ).

Some of those working on the disability side thought that a distinction was appropriate between the aims of policy for disabled people under and over 65, and, in discussing this, demonstrated how the funding boundary affected their understanding. Thus one manager of services for disabled people approved of the disability policy New Directions, which, as he explained it, aims to support people to access 'employment and education and community' and as 'a personal support

\footnotetext{
${ }^{3}$ While this participant used the term 'social model' approach to disability, she also made it clear that by this she means disability as the interaction between impairments and social and environmental factors and she specifically related her understanding to the definition in the U.N. Convention on the Rights of Persons with Disabilities, which can be characterised as a psychosocial definition.
} 
to have a life'. He felt that this approach was not appropriate to disabled people over 65 . He added that he could possibly envisage this approach for long-term disabled people already within disability services, but not for other people aged over 65 . He explained this in terms of the funding boundary and funding constraints within which he works, which made it impossible for him to envisage taking on an additional client group.

Later in the interview this participant identified contradictions in his thinking, saying that people had the right after age 65 to have 'a full life'. He added, 'I'm blocked in my 65 s ....over 65 s,' and went on to outline how the separate funding streams dictate and limit thinking on the issue:

I think most people over 65, a lot of them will have a disability of some sort. ... the different definitions of disability would capture a lot of people over $65 \ldots$ but they are not seen as disabled people. They are seen as elderly ... It seems very hard to shake your way out of it ... you'd have to say it's illogical actually to have that divide, because a 66 year old has the same needs as a 63 year old ... and might now have an impairment or a limited functioning ... that would qualify them as a disabled person if they were under 65 (Service Provider 1, disability).

Thus, during the interview he identified contradictions in his thinking about the chronological boundary of age 65 , thinking that is embedded within the organisational and funding structure within which he works and which affects how disability is understood and how services are conceived of for the two groups.

This participant's thinking reflects institutional structures that mean that 'the status of the disability is bureaucratically 'frozen' (Rickli, 2016:126-7). Thus, it illustrates how the administrative/funding boundary constructs the lifecourse and the meaning attached to the experience of impairment at different life-stages. In the thinking of this participant, it creates a distinction between people who belong to the same chronological cohort but with different timings of disability onset - with those whose disability onset predated their $65^{\text {th }}$ birthdays being more likely to continue to be considered 'disabled.' For that reason he would consider it more appropriate for them to be included within more socially-orientated disability services.

The findings point to anomalies in practice where a small difference in timing of disability onset around one's 65th birthday may determine an engagement with services that are conceived of and delivered differently.

\section{Conceptualisation of Services for older people and for disabled people}

The second key category identified in the data concerns how services were conceived of or delivered for older people and disabled people and whether participants perceived the differences to be appropriate.

In general, participants highlighted how a more medicalised and less self-directed approach was a feature of older people's services. Those working within older people's services critiqued this as did several of those working in disability. However, some of those working on disability outlined how they perceived certain differences as appropriate, and this related to how they understood disability and ageing.

\section{Older people's services - narrow and medicalised rather than holistic}

Most people felt that older people's services were over-medicalised and too narrowly focused on basic physical functioning, ignoring, in particular, emotional and social sides of older people's lives. Public provision for older people was perceived to overlook issues of participation, companionship and emotional needs - perceived of as often being considerable as people adjusted to changes in functioning.

A manager of services for older people within the national health service described the emphasis on 'maintenance'. He considered that, by contrast, services for younger disabled people would include a focus on participation as a right:
... if you acquire a disability as an older person, the care and support is based around literally the maintenance of immediate activity of daily living ... this would focus on your ability to get up washed and dressed, fed, and that would be about the sum of it. But if you have got a disability and you are younger then there might be more thinking about the fact that you continue to have a human right to participate in society, to be able to get to the shops, to be able to go to events ... but once you turn 65 that doesn't exist (Service Provider, ageing 1).

He instanced conflict with clinical staff about what home support should include. Whereas he felt that walking someone's dog or taking them to a religious service (if they chose it) was person-centred care, clinical staff considered this as too broad. He attributed this to prioritisation of scarce resources through the lens of a narrow medical model. This echoes criticism from gerontologists of the narrow focus on functioning in public policies and practices. For example, Lloyd (2012:113) argues that too narrow a focus on what constitutes an activity of daily living 'ignores relationships and quality of life.'

As already outlined, a small number of those on the disability side thought that differences were appropriate in the approach to services for the two groups - specifically, that more medicalisation and less focus on community participation was appropriate within older people's services. This was associated with an understanding of disability in older age as tantamount to decline and end of life, as already discussed, above, and with an assumption that older people already have 'natural' family and community supports.

\section{Disability services - independence and self direction?}

In contrast to older people's services, disability services were thought to aim to provide a more comprehensive range of services, including rehabilitative approaches, and to operate in a more flexible and self-directed way. This was considered an appropriate aim. However, it was also described as limited in practice by those working on disability. Instead, for most people, an administrative system was described as still operating:

The HSE [national health service] decides how many hours [of support to live at home]. Only a very tiny number of people have a personal budget where they go off and they do their own [thing] ... (Policy-maker/advisor, disability 1 ).

Instances were given of younger disabled people experiencing insufficient supports to live at home and a lack of rehabilitative therapies. Perceived gaps in services were similar for both groups, chief amongst them being the underdevelopment of community care services and a related biasing towards residential care.

A medicalised approach was also said to operate at times within disability services - and participants perceived this as sometimes inappropriate and sometimes as an appropriate response to significant medical needs. The exigencies of that care were perceived as contrasting with the lower levels of support that might be needed for an older person to live at home, such as help with some tasks like washing or dressing, but who might otherwise be able to perform activities of daily living independently.

This perception is perhaps ironic given the medicalised emphasis in older people's services and, indeed, the views of some of these same participants from the disability side that this was appropriate for older people.

\section{Perceptions of the separation between the two services}

Finally, I will outline how well participants perceived the division between the two services to be serving their client groups. This was not something that all participants had considered to any extent prior to interviews and a small number did not have a view on the issue.

But several participants described the strict division between ageing 
and disability approaches as illogical and cumbersome, not delivering person-centred care/support, and creating anomalies for some groups. An 'opaque glass wall' was described as operating between the two sectors - amongst statutory organisations and amongst NGOs - which resulted in neither learning much from the other.

Those thought to be disadvantaged by the division included people diagnosed with dementia prior to age 65 who could experience difficulty accessing appropriate services - as dementia services are located within older people's services. For people who experienced disability before age 65 and were connected to disability services, there seemed to be variation in practice as to what happens once they turn 65 . They often, it seems, remain within disability services, so they might continue, for example, to attend a day centre. But the practice of transferring people ageing with disability upon reaching age 65 from social care provided by disability services to home care provided by older people's services was known to operate in some parts of the country or on a discretionary basis. This was highlighted by a participant from a national disability organization. In this participant's view, the transfer represented a shift from a case managed, rehabilitation-based service to a purely task-based 'care' model that was not as comprehensive, responsive or appropriate to the needs of the clients in question.

Some participants voiced caution voiced lest attempts be made to integrate the two services that would in reality aim to save costs and result in a diminution of services for one or both groups. One person emphasised the need for conceptual change around how disability is conceived of as a prerequisite for change:

... any attempt to make service change without first really interrogating attitudinal constructs is doomed to repeat the failures of the past or the exclusions of the past (Policy-maker/advisor, disability 2).

These are legitimate concerns. Building and sustaining bridges between the two fields is not simple (Putnam, 2007). For example, Walker and Walker (1998) illustrated how ageist assumptions and stereotypes built into 'normal' patterns of care for older people operated destructively when applied to those ageing with lifelong disability. Looking at the situation of community-dwelling people ageing with learning difficulties, they (1998:127) describe how as soon as an individual is transferred from one service category to another due to chronological ageing, 'the orientation of services shifts from supporting independence to reproducing dependence'. In short, it is obvious why advocacy for disabled people attempts to link rights for disabled people to those aimed at children and adults below retirement age - to be considered entitled to the full participation and activity afforded to adults (Jönson \& Larsson, 2009).

\section{Discussion}

This article reported on a study with people working in social care in policy-making, service provision and activism on ageing and on disability in Ireland. It highlighted some conceptual issues and practice anomalies related to the administrative and funding boundary between disability and older people's services.

The study found that participants often had no concept of disability with ageing, and identified older people acquiring impairment with terms like 'just elderly'. A 'disabled older person' was often understood to be someone who was ageing having lived with lifelong disability. This reflects how 'disability' as a status is bureaucratically 'frozen' (Rickli, 2016:126-27). This represented a paradox for some participants, who rejected a conflation of the concept of older age and disability, frailty illhealth or functional restrictions and sought to distinguish the majority of older people from this image. Yet they also did not have a language with which to talk about older people who do experience onset of impairments or disability, other than it being implicit in some understandings of what it is to be older and marginalised or isolated.

Some participants working in disability equated the experience of disability with ageing with decline and end of life. Others, by contrast, invoked a biopsychosocial model of disability by reference to the U.N. Convention on the Rights of Persons with Disabilities. This, they believed, encompassed and conferred rights on those experiencing disability-onset for the first time with ageing as well as those ageing with long-standing disability.

Participants often highlighted how a more medicalised and less selfdirected approach was a feature of older people's services and most participants critiqued this. By contrast, the aims for disability programmes were considered to focus more on self-direction and community involvement. But similar gaps in services were identified for the two groups, including the underdevelopment of community services.

Understandings of impairment or disability in older age were embedded within segmented institutional and funding arrangements, which influenced thinking about distinct types of supports and services being appropriate to the two groups. For example, some of those within disability services perceived that a model which focused on community involvement was appropriate for disabled people, not older people, something associated with funding constraints and service pressures. In one case this led to a participant considering that a distinction might be appropriate between older people with different timings of disability onset; he considered it potentially appropriate that those already within disability services at age 65 be included within socially-orientated disability services thereafter, but not other people of the same age first experiencing disability after age 65. However, during interviews this and other participants identified contradictions in their approach to these issues embedded within the existing configuration of services.

The findings point to a number of issues and anomalies not just at the level of conceptualisation but also in practice. Those who experience disability for the first time in later life may only encounter older people's services, and thus a small difference in timing of disability onset around one's 65th birthday may result in experiencing a different service model. For those ageing with disability, upon reaching age 65 there could be continuity in social care provision, or there could be disruption and perceived diminution of services if they were transferred to older people's services, a practice that appeared to be operating in some geographical areas or on a discretionary basis. And some, experiencing conditions like dementia prior to age 65, could appear to fall between the two systems, having difficulties accessing the appropriate 'older people's' services.

I now turn to discuss some of the study's theoretical and policy implications.

The issues and anomalies evident from the findings illustrate the need to critically engage with ageist assumptions that underlie the provision of aged-care. Findings also suggest how unconscious ableism as well as ageism may be operating. Specifically, elements of ableism and ageism, respectively, can be seen in the distancing by those working on ageing from concepts like disability, and the equating of older age and end of life (and consequent downplaying of social needs) by some of those working on disability. This illustrates how, 'mutual discrimination is to some extent present in the very struggle against ageist and ablest norms' (Jönson \& Larsson, 2009:75). Findings are also consistent with Priestley's (2006) argument that movements both for independent living and active ageing have distanced themselves from the negative imagery of dependency in deep older age.

Thus, issues of ageism and ableism as well as a level of professional investment in age-segmented policies and programmes need, and do not always receive I suggest, attention as part of changes or integration of approaches between aged and disability social-care programmes. These findings and others (for example, Keefe, 2014; Putnam, 2011) suggest that professional training and support and ongoing technical support would be necessary to facilitate working with unfamiliar client groups.

This study's findings underscore the need for more information exchange between disability organisations and older people's organisations, as Priestley and Rabiee (2002) argued in the U.K. context. Findings also support Priestley's (2002) argument that different 
language, reflecting different understandings, represents an obstacle to closer working between representative groups of disabled and older people, despite areas of common ground. However, these findings also point to how cultural interpretations can be partly shaped, or underlined, by policy and services, something that can in turn reinforce a 'disabled' identity for some groups (Grenier et al., 2016). Furthermore, that there is scope for these groups to identify common ground is perhaps signalled by a study that found similarities between voices associated with the social model of disability and those of older women who experienced their homes and public transport as disabling (Grenier, 2005). At a fundamental level, the findings suggest the need to find ways in common across the two sectors of articulating what it is to experience disability in older age.

Participants in this study working on ageing (and some of those working on disability) criticised the over-medicalisation of social care for older people and the lack of attention to people's social needs, echoing criticism from gerontologists that social care practices for older people based on the medical model are often overtly or covertly ageist (Heywood, Oldman, \& Means, 2002; Oldman, 2002). But over-medicalisation is also precisely the critique in relation to disability generally that was mounted by disability activists from the 1960s. Brisenden ([1986]1998:20) described the medical model of disability thus:

The medical model of disability is one rooted in an undue emphasis on clinical diagnosis, the very nature of which is destined to lead to a partial and inhibiting view of the disabled individual.

Associated with such critiques, the social model of disability emerged and it has been an 'emancipatory force' with 'profound practical, as well as theoretical application' (Tregaskis, 2002; 457). Even Shakespeare $(2006: 13,30)$, who is a critic of what he calls the 'strong social model, ${ }^{4}$ recognises its value in having widened the focus from studying individuals 'to exposing broader social and cultural processes'. There are debates between scholars/activists about social and biopsychosocial approaches to disability (see Goodley, 2011). However, the point I emphasise here is how both approaches reject a view of disability as the sole result of individual differences or biology and instead encompasses social causes, including physical environments, social structures and cultural representation (for examples, see Nagi, 1965; Morris, 1991; Hahn, 1993; Finkelstein, 1998; Oliver, 1990, 1996; Shakespeare, 2006, 2013).

By contrast, the focus on sociogenic factors in social and biopsychosocial approaches to disability is often absent in discussions of the experience of disability with ageing. The dominance of medical definitions of the problems faced in older age leaves little room for, amongst other things, critical analysis of disabling social environments or structures of care provision or social policy (Estes, Biggs, \& Phillipson, 2003). Instead, gerontologists often talk about disability as if it were a personal characteristic or a permanent attribute (something a person has rather than experiences), not something experienced in and contributed to by the environment (Putnam, 2002). And in policy and other domains, there has been an over-reliance on organismic ageing processes as the explanatory framework for disablement to the exclusion of social structural influences (Kelley-Moore, 2010:107).

The power of models of disability is rarely acknowledged, yet they define disability, determine which professions are engaged, and help shape self-identities (Smart, 2009). The medical model has 'scarcely been challenged' in policies on ageing (Oldman, 2002:795) and influential paradigms like successful ageing are based on it (Holstein \& Minkler, 2007:15). Walker (2014:9) characterises the fact that some

\footnotetext{
${ }^{4}$ For Shakespeare (2006), while a social approach to disability is indispensable, it does not have to take the particular form of the British social model with its strict binary between impairment and disability - the latter considered completely socially constructed. Shakespeare (2006:59) discusses several social models, aligning his position to the Nordic relational approach and to the 'medico-psycho-social model' enshrined in the WHO International Classification of Functioning, Disability and Health (IFC).
}

older people suffer from chronic conditions that dominate their lives as 'disability rather than old age.' This is true. It is also true that it would be a pity if concerns about it being 'ageist' to associate older age with disability, 'help transfer fears about aging to fears of disability' (Kennedy \& Minkler, 1999:101).

There is some focus now on ageing within disability studies. For example, Davis (2013) argues that there is a need to identify how older people define disability, and Priestley (2006) points to the risk that those who are oldest and most marginalised are also those being left behind in the struggle for disability equality. Some disability scholars recognise that an older person may experience marginalisation on account of both age and disability (Morris, 2001: Riddell \& Watson, 2003). Riddell and Watson (2003:16) have said:

There is no point in developing positive images of disabled people if older people continue to be socially devalued.

But perhaps the converse is also true - that there is no point in developing positive images of older people if disabled people continue to be socially devalued?

Priestley (2003a, 2003b, 2006) and Shakespeare (2006) are amongst those writing within disability studies who engage with disability across the lifespan. For Shakespeare (2006) a lifecourse approach recognises changes over time with non-disabled people becoming impaired through accident or in older age. He considers that the WHO's bio-psychosocial approach is a 'sensible and practical way of understanding the complexity of disability' (Shakespeare, 2006:59). Thus, this approach to definition is considered consistent with critical disability theory (Hosking, 2008). Likewise, writing in the Gerontologist, Hagestad and Settersten (2017:143) highlight the value of the WHO approach to understanding disability as a relation between individual capacity and environmental demands, because of how 'reduced functioning brings the danger of either/or thinking....and threatens the potential for social participation and contribution'.

Several participants in this study working on disability already employ an understanding of the category 'disability' that could encompass people experiencing disability for the first time in older age. These participants tended to understand disability by reference to the definition in the U.N. Convention on the Rights of Persons with Disabilities. The Convention is linked to the WHO international classifications (IFC) and both involve a universal, bio-psychosocial approach to disability, and a relational definition that seeks to bridge medicalised approaches and social models (see Article 1, quoted above). Bio-psychosocial definitions recognise that the entire population is 'at risk' for chronic illness and disability (Bickenbach, Chatterji, Badley, \& Ustun, 1999:1185).

But the Convention is not widely applied to older people and limited views of what constitutes 'disability' are thought to play a role in this (European Network of National Human Rights Institutions, 2016 ${ }^{5}$ ). I suggest that universal, biopsychosocial understandings of disability may offer a conceptual framework to facilitate necessary linkages between policy and practice, research and activism on ageing and disability.

It would be unfortunate if problems associated with how the personalised social care agenda has been implemented for older people (in the U.K. at any rate), were to block greater interchange between the fields of disability and ageing. On the contrary, these problems underline the need for greater interrogation of the implicit and explicit understandings that inform them: that is, investigation of the 'opaque glass wall' operating between the two. Both demographic ageing and the greater longevity of people experiencing lifelong disability should operate as a spur to this.

I suggest that this discussion could be moved on if (1) there was

\footnotetext{
${ }^{5}$ Especially Article 19, which provides for the right to live independently and be included in the community.
} 
more understanding of the concept of disability (and cognate concepts) in older age in ways that do not simply equate them with impairment, (2) if social constructions of disablement processes in older age were more widely understood, and (3) if research, policy and practice linked more closely with disabled older people both experiencing disability with ageing and ageing with disability. Greater familiarly amongst those working on ageing issues with concepts from disability studies might facilitate this, especially, that is, relational approaches to disability that understand it as occurring in the interaction between the bodily and the contextual. This is because of its possible efficacy both as an analytical construct and as a political argument.

\section{Conclusions}

While the strict funding boundary operating within health and social care in Ireland is considered illogical, inflexible, and not delivering person-centred care or support by people working in the fields of disability and ageing, it is also true that the separation of the two services is underpinned by conceptual issues, including the lack of a concept of disability with ageing. In this study, participants simultaneously acknowledged that people experienced impairment or disability with ageing but were not seen as 'disabled', just 'elderly' or 'older'. This represents a paradox for some who identify with successful or active ageing concepts that seek to distinguish the majority of older people from an image of disability, frailty or functional restrictions. This paradox occurs because they lack concepts or a language with which to discuss older people who do experience onset of impairments or disability. It becomes unspoken and almost unspeakable.

It informs and is reinforced in turn by the separate funding and organization of ageing and disability policies and services, which helps to construct thinking in separate terms about disability and ageing and leads to contradictions and anomalies in practice. Elements of ageism and ableism contribute to the maintenance of barriers to closer working between the two sectors.

A small number of people within the disability sector felt that older people's services were dealing with decline and end of life and for that reason were appropriately more medicalised and less socially focused than disability services generally. However, most study participants critiqued the over-medicalisation of services for older people and the consequent inattention to social and other needs. That critique is similar to the critique traditionally made by disability activists and associated with younger disabled people. I query if insights from the disability movement and from critical disability scholars, and especially biopsychosocial models of disability, might assist those working on ageing to navigate a course between what Holstein and Minkler (2007:15) describe as the 'twin poles of ageing - its strengths and weaknesses; its celebrations and pains'.

In particular, I suggest that universal, biopsychosocial understandings of disability, associated with the WHO family of international classifications such as the U.N. Convention on the Rights of Persons with Disabilities, could facilitate the encompassing of people experiencing disability with ageing within the category of 'disabled people' and provide a common language between the two sectors. These approaches could help create conditions for collective responses to people experiencing disability and ageing (irrespective of time of onset) and for understandings that avoid a return to an equation between older age and impairment, disability or decline. It also offers the potential to address what may be 'false dichotomies' operating between the two sectors.

Participants were apprehensive that moves towards integration of the two services would result in a diminution of current levels of support for one or both groups. Ireland is embarking on the introduction of a personalised approach to social care, which elsewhere appears to have been implemented without ensuring that improvements are delivered for all user groups. I have argued that preconceptions of staff are embedded within existing segmented policies, something, along with separate philosophical underpinnings and other issues, that should be interrogated as part of any proposed changes or integration of approaches between older people's and disability programmes.

\section{Acknowledgements}

The research reported here was funded by a doctoral scholarship from the Irish Research Council (EBPPG/2013/58). A presentation made at the British Society of Gerontology Annual Conference in Stirling, Scotland, on 7 July 2016 formed the basis for the paper. Thanks are due to Professor Jane Gray, Department of Sociology, Maynooth University, Ireland who made helpful comments on an earlier draft. I also thank two anonymous reviewers for their comments.

\section{References}

Abberley, P. (1998). The spectre at the feast: Disabled people and social theory. In T. Shakespeare (Ed.). The disability reader: Social science perspectives. London: Cassell.

Active Ageing Partnership, Age Action, Age \& Opportunity, Alone, Alzheimer Society of Ireland, Care Alliance Ireland, Disability Federation of Ireland, Family Carers Ireland, Irish Association of Social Workers, Irish Hospice Association, Migrant Right Centre of Ireland, MS Ireland, Sage-Support \& Advocacy Service, \& Third Age (2017). Discussion document on the consultation process for the establishment of a statutory homecare scheme. 19 April. Online https://www.ageaction.ie/news/2017/04/24/ campaigners-unite-ahead-homecare-consultation Retrieved 14 August 2017

Anand, J. C., Davidson, G., Macdonald, G., \& Kelly, B. (2012). The transition to personal budgets for people with disabilities: A review of practice in specified jurisdictions. Dublin: National Disability Authority. http://nda.ie/nda-files/The-Transition-to-PersonalBudgets-For-People-with-Disabilities-A-Review.

Anttonen, A., \& Sipila, J. (1996). European social care services: Is it possible to identify models? Journal of European Social Policy, 6(2), 87-100.

Beresford, P. (2008). What future for care? York: Joseph Rowntree Foundation.

Bernard, R. H., \& Ryan, G. W. (2010). Analysing qualitative data: Systematic approaches. U.S., California: Sage.

Bickenbach, J. E., Bigby, C., Salvador-Carulla, L., Heller, T., Leonardi, M., LeRoy, B., .. Spindel, A. (2012). The Toronto declaration on bridging knowledge, policy and practice in aging and disability: Toronto, Canada, March 30, 2012. 12. International Journal of Integrated Care.

Bickenbach, J. E., Chatterji, S., Badley, E. M., \& Ustun, T. B. (1999). Models of disablement, universalism and the international classification of impairments. Social Science \& Medicine, 48(9), 1173-1187.

Bigby, C. (2002). Ageing people with a lifelong disability: Challenges for the aged care and disability sectors. Journal of Intellectual and Developmental Disability, 27(4), $231-241$.

Bigby, C. (2008). Beset by obstacles: A review of Australian policy development to support ageing in place for people with intellectual disability. Journal of Intellectual and Developmental Disability, 33(1), 76-86.

Bishop, K. A., \& Hobson, S. J. G. (2015). Perceptions of aging for persons with adult-onset disability. Journal of Canadian Gerontological Nursing Association, 37(4).

Bowling, A., Farquhar, M., \& Grundy, E. (2008). Associations with changes in level of functional ability. Results from a follow-up survey at two and a half years of people aged 85 years and over at baseline interview. Ageing and Society, 14(1), 53-73. http://dx.doi.org/10.1017/S0144686X00000052.

Brisenden, S. (1986). Independent living and the medical model of disability. In T. Shakespeare (Ed.). The disability reader social science perspectives (pp. 20-27). London: Cassell.

Charmaz, K. (2005). Grounded theory in the 21st century: Applications for advancing social justice. In N. K. Denzin, \& Y. Lincoln (Eds.). The Sage handbook of qualitative research (pp. 507-536). Thousand Oaks, CA: Sage.

Charmaz, K. (2014). Constructing Grounded Theory. London/Los Angeles: Sage.

Connolly, S. (2015). Contextualising Ageing in Ireland. In K. Walsh, G. M. Carney, \& A. Ni Leime (Eds.). Ageing through austerity: Critical perspectives from Ireland (pp. 17-30). Bristol: Policy Press.

Conroy, P., \& Mangan, I. (2006). Ageing \& disability: A discussion paper. Dublin: National Disability Authority and National Council on Ageing and Older People.

Cooper, M., \& Bigby, C. (2014). Cycles of adaptive strategies over the life course. Journal of Gerontological Social Work, 57(5), 421-437.

Dannefer, D., \& Settersten, R. A. (2010). The study of the life course: Implications for social gerontology. In D. Dannefer, \& C. Phillipson (Eds.). The Sage handbook of social gerontology. London: Sage.

Davis, L. J. (2013). The end of identity politics: On disability as an unstable category. In L J. Davis (Ed.). The disability studies reader. New York and Oxon: Routledge.

Denzin, N. K., \& Lincoln, Y. S. (2000). The discipline and practice of qualitative research. In N. K. Denzin, \& Y. S. Lincoln (Eds.). Handbook of qualitative research. London: Sage publications.

Department of Health (2015). Review of the nursing homes support scheme, a fair deal. Dublin: Department of Health.

Department of Health (2016). Information note: Establishment of taskforce on 
personalised budgets. 1 August (Retrieved 12 December 2016). Online http://health. gov.ie/blog/noticeboard/task-force-on-personalised-budgets/.

Department of Health (2017). Consultation on home care services. 6 July. (Retrieved 14 August 2017) http://health.gov.ie/blog/noticeboard/consultation-on-home-careservices/.

De Schauwer, E., Van de Putte, I., Claes, L., Verstichele, M., \& Davies, B. (2016) Schildrick's monster: Exploring a new approach to difference/disability through collective biography. Disability \& Society, 31(8), 1098-1111.

Duffy, S. (2012). Is personalisation dead? Sheffield: Centre for Welfare Reform. Retrieved July 14, 2016 http://www.centreforwelfarereform.org/library/by-az/ispersonalisation-dead.html.

Estes, C. L., Biggs, S., \& Phillipson, C. (2003). Social theory, social policy and ageing: A critical introduction. Buckingham: Open University Press.

European Network of National Human Rights Institutions (2016). The CRPD and older persons with disabilities: The transition to community-based long-term care services. Brussels: ENNHRI.

Expert Reference Group on Disability Policy (2010). Report of disability policy review. Prepared by Fiona Keogh on behalf of the group. December.

Finkelstein, V. (1998). Emancipating disability studies. In T. Shakespeare (Ed.). The disability reader: Social science perspectives (pp. 28-49). London: Cassell.

Freedman, V. A. (2014). Research gaps in the demography of aging with disability. Disability and Health Journal, 7(1), S60-S63.

Gibbons, H. M. (2016). Compulsory youthfulness: Intersections of ableism and ageism in "successful aging" discourses. Review of Disability Studies: An International Journal, $12(2 \& 3)$.

Glasby, J. (2011). Whose risk is it anyway? Risk and regulation in an era of personalisation. York: Joseph Rowntree.

Glasby, J., \& Littlechild, R. (2016). Direct payments and personal budgets: Putting personalisation into practice. London: Policy Press.

Glendinning, C., Challis, D., Fernández, J. L., Jacobs, S., Jones, K., Knapp, M., ... Wilberforce, M. (2008). Evaluation of the individual budgets pilot programme: Summary report. York: Social Policy Research Unit, University of York.

Goodley, D. (2011). Disability studies: An interdisciplinary introduction. London: Sage.

Graby, S. (2015). Neurodiversity: Bridging the gap between the disabled people's movement and the mental health system survivors' movement? In H. Spandler, J. Anderson, \& B. Sapey (Eds.). Madness, distress and the politics of disablement. London: Policy Press.

Graham, K. (2015). Cash payments in context: (self-) regulation in the new social relations of assistance. Disability \& Society, 30(4), 597-613.

Grenier, A. M. (2005). The contextual and social locations of older women's experiences of disability and decline. Journal of Aging Studies, 19(2), 131-146.

Grenier, A., Griffin, M., \& McGrath, C. (2016). Aging and disability: The paradoxical positions of the chronological life course. Review of Disability Studies: An International Journal, 12(2\&3).

Hagestad, G. O., \& Settersten, R. A. (2017). Aging: It's interpersonal! Reflections from two life course migrants. Gerontologist, 57(1), 136-144.

Hahn, H. (1993). The political implications of disability definitions and data. Journal of Disability Policy Studies, 4(2), 41-52.

Henning-Smith, C. (2016). Where do community-dwelling older adults with disabilities live? Distribution of disability in the United States of America by household composition and housing type. Ageing and Society, 37(6), 1227-1248.

Heywood, F., Oldman, J., \& Means, R. (2002). Housing and home in later life. Buckingham: Open University Press.

Higgs, P., \& Gilleard, C. (2015). Rethinking old age: Theorising the fourth age. London: Palgrave Macmillan.

Holstein, M. B., \& Minkler, M. (2007). Critical gerontology: Reflections for the 21st century. In M. Bernard, \& T. Scharf (Eds.). Critical perspectives on ageing societies (pp. 13-26). Bristol: Policy Press.

Hosking, D. L. (2008). Critical disability theory. 4th Biennial disability studies conference. Lancaster: University, UK.

Jönson, H., \& Larsson, A. T. (2009). The exclusion of older people in disability activism and policies - A case of inadvertent ageism? Journal of Aging Studies, 23(1), 69-77. http://dx.doi.org/10.1016/j.jaging.2007.09.001.

Kane, R., \& Kane, R. (2005). Ageism in healthcare and long-term care. Generations, 29(3), 49-54.

Keefe, B. (2014). Can a service philosophy be identified in aging and disability resource centres? A study of institutional logics as applied to the creation of new hybrid organizations. PhDBoston University3626146.

Kelley-Moore, J. A. (2010). Disability and ageing: The social construction of causality. In D. Dannefer, \& C. Phillipson (Eds.). The Sage handbook of social gerontology (pp. 96110). London: Sage.

Kelley-Moore, J. A., Schumacher, J. G., Kahana, E., \& Kahana, B. (2006). When do older adults become "disabled"? Social and health antecedents of perceived disability in a panel study of the oldest old. Journal of Health and Social Behavior, 47(2), 126-141.

Kennedy, J. (2000). Responding to the disparities between disability research and aging research. Journal of Disability Policy Studies, 11(2), 120-123.

Kennedy, J., \& Minkler, M. (1999). Disability theory and public policy: Implications for critical gerontology. In M. Minkler, C. Estes, \& L. New (Eds.). Critical gerontology: Perspectives from political and moral economy. York: Baywood Publishing Company Inc.

LaPlante, M. P. (2014). Key goals and indicators for successful aging of adults with earlyonset disability. Disability and Health Journal, 7(1), S44-S50.

Le Bihan, B. (2016). France anticipates ageing society through new piece of legislation: ESPN Flash Report 2016/18. European social policy network. Brussels: European Commission.

Lloyd, L. (2010). The individual in social care: The ethics of care and the 'personalisation agenda' in services for older people in England. Ethics and Social Welfare, 4(2), $188-200$.

Lloyd, L. (2012). Health and care in ageing societies: A new international approach. Bristol: Policy Press.

Lloyd, L., Calnan, M., Cameron, A., Seymour, J., \& Smith, R. (2014). Identity in the fourth age: Perseverance, adaptation and maintaining dignity. Ageing and Society, 34(01), $1-19$.

Maxwell, J. A. (2008). Designing a qualitative study. In L. Bickman, \& D. J. Rog (Eds.). The handbook of applied social research methods (pp. 214-250). (second edition). Thousand Oaks CA: Sage Publications.

McGrath, C., Rudman, D. L., Trentham, B., Polgar, J., \& Spafford, M. M. (2017). Reshaping understandings of disability associated with age-related vision loss (ARVL): Incorporating critical disability perspectives into research and practice. Disability and Rehabilitation, 39(19), 1990-1998.

Monahan, D. J., \& Wolf, D. A. (2014). The continuum of disability over the lifespan: The convergence of aging with disability and aging into disability. Disability and Health Journal, 7(1 Supplement), S1-S3. http://dx.doi.org/10.1016/j.dhjo.2013.10.002.

Morris, J. (1991). Pride against prejudice: Transforming attitudes to disability: A personal politics of disability. London: The Women's Press Ltd.

Morris, J. (1993). Independent lives? Community care and disabled people. London: Macmillan.

Morris, J. (2001). Impairment and disability: Constructing an ethics of care that promotes human rights. Hypatia, 16(4).

Morris, J. (2006). Independent living: The role of the disability movement in the development of government policy. In C. Glendinning, \& P. A. Kemp (Eds.). Cash and care: Policy challenges in the welfare state (pp. 235-248). Bristol: Policy Press.

Murphy, K., O'Shea, E., Cooney, A., \& Casey, D. (2007). The quality of life of older people with a disability in Ireland. Report no. 99. Dublin: National Council on Ageing and Older People.

Nagi, S. Z. (1965). Some conceptual issues in disability and rehabilitation. In M. Sussman (Ed.). Sociology and rehabilitation (pp. 100-113). Washington DC: American Sociological Association.

Naidoo, V., Putnam, M., \& Spindel, A. (2012). Key focal areas for bridging the fields of aging and disability: Findings from the growing older with a disability conference. International Journal of Integrated Care, 12.

National Audit Office (2016). Personalised commissioning in social care. Report by the comptroller and auditor general. London: HMSO.

Nicholson, C., Meyer, J., Flatley, M., \& Holman, C. (2013). The experience of living at home with frailty in old age: A psychosocial qualitative study. International Journal of Nursing Studies, 50(9), 1172-1179. http://dx.doi.org/10.1016/j.ijnurstu.2012.01. 006.

O'Donnell, P. (2007). Disability and society: Ideological and historical dimensions. Dublin: Blackhall Publishing.

Oldman, C. (2002). Later life and the social model of disability: A comfortable partnership? Ageing and Society, 22(06), 791-806.

Oliver, M. (1990). The politics of disablement. Basingstoke: Macmillan.

Oliver, M. (1996). Understanding disability: From theory to practice. Basingstoke: MacMillan Press.

O'Shea, E., Cahill, S., \& Pierce, M. (2015). Reframing policy for dementia. In K. Walsh, G. Carney, \& A. Ni Leime (Eds.). Ageing through austerity. Policy Press.

Priestley, M. (2002). Whose voices? Representing the claims of older disabled people under new labour. Policy \& Politics, 30(3), 361-372.

Priestley, M. (2003a). Disability: A life course approach. Cambridge: Polity.

Priestley, M. (2003b). 'It's like your hair going grey', or is it? Impairment, disability and the habitus of old age. In S. Ridddell, \& N. Watson (Eds.). Disability, culture and identity (pp. 53-66). Essex, U.K.: Pearson.

Priestley, M. (2006). Disability and old age: or why it isn't all in the mind. In D. Goodley, \& R. Lawthom (Eds.). Disability and psychology: Critical introductions and reflections (pp. 84-93). Basingstoke and New York: Palgrave MacMillian.

Priestley, M., \& Rabiee, P. (2001). Building bridges: Disability and old age. End of award report: ESRC small grant number: Rooo223581. Leeds: University of Leeds.

Priestley, M., \& Rabiee, P. (2002). Same difference? older people's organisations and disability issues. Disability \& Society, 17(6), 597-611.

Putnam, M. (2002). Linking aging theory and disability models: increasing the potential to explore aging with physical impairment. The Gerontologist, 42, 799-806.

Putnam, M. (2007). Moving from separate to crossing aging and disability service net works. In M. Putnam (Ed.). Aging and disability crossing network lines. New York: Springer.

Putnam, M. (2011). Perceptions of difference between aging and disability service systems consumers: Implications for policy initiatives to rebalance long-term care. Journal of Gerontological Social Work, 54(3), 325-342. http://dx.doi.org/10.1080/ 01634372.2010 .543263$.

Putnam, M. (2014). Bridging network divides: Building capacity to support aging with disability populations through research. Disability and Health Journal, 7(1), S51-S59. http://dx.doi.org/10.1016/j.dhjo.2013.08.002.

Rabiee, P., Baxter, K., \& Glendinning, C. (2016). Supporting choice: Support planning, older people and managed personal budgets. Journal of Social Work, 16(4), 453-469. http://dx.doi.org/10.1177/1468017315581529.

Raymond, É., Grenier, A., \& Hanley, J. (2014). Community participation of older adults with disabilities. Journal of Community and Applied Social Psychology, 24(1), 50-62.

Rickli, F. (2016). No longer disabled-Reflections on a transitional process between disability and aging in Switzerland. Review of Disability Studies: An International Journal, $12(2 \& 3)$.

Riddell, S., Priestley, M., Pearson, C., Mercer, G., Barnes, C., Jolly, D., \& Williams, V. (2006). Disabled people and direct payments: A UK comparative study. ESRC end of award report RES-000-23-0263. 
Riddell, S., \& Watson, N. (2003). Disability, culture and identity: Introduction. In S. Riddell, \& N. Watson (Eds.). Disability, culture and identity. Essex, UK: Pearson.

Salvador-Carulla, L., Balot, J., Weber, G., Zelderloo, L., Parent, A.-S., McDaid, D., ... Participants at the Conference (2009). The Barcelona declaration on bridging knowledge in long-term care and support. Barcelona (Spain), March 7, 2009. International Journal of Integrated Care, 9, 1-2.

Shakespeare, T. (2006). Disability Rights and Wrongs. London: Routledge.

Shakespeare, T. (2013). The Social Model of Disability. In L. J. Davis (Ed.). The disability studies reader. New York and Oxon: Routledge.

Slasberg, C., \& Beresford, P. (2016). The false narrative about personal budgets in England: Smoke and mirrors? Disability \& Society, 31(8), 1131-1137.

Smart, J. F. (2009). The power of models of disability. Journal of Rehabilitation, 75(2), 3-11.

Strauss, A., \& Corbin, J. (1998). Basics of qualitative research: Techniques and procedures for developing grounded theory. Thousand Oaks, CA: Sage.

Timonen, V. (2016). Beyond successful and active ageing: A theory of model ageing. Bristol: Policy Press.

Timonen, V., Convery, J., \& Cahill, S. (2006). Care revolutions in the making? A comparison of cash-for-care programmes in four European countries. Ageing and Society, 26(3), 455-474.

Timonen, V., Doyle, M., \& Prendergast, D. (2006). No place like home: Domiciliary care services for older people in Ireland. Dublin: Liffey Press.

Townsend, P. (1981). Elderly people with disabilities. In A. Walker, \& P. Townsend (Eds.). Disability in Britain: A manifesto of rights. Oxford: Martin Robertson.

Tregaskis, C. (2002). Social Model Theory: The story so far... Disability \& Society, 17(4), $457-470$.

United Nations General Assembly (2006). Final report of the ad hoc committee on a comprehensive and integral international convention on the protection and promotion of the rights and dignity of persons with disabilities. A/61/611. 6 December.
Verbrugge, L. M., \& Yang, L.-s. (2002). Aging with disability and disability with aging. Journal of Disability Policy Studies, 12(4), 253-267.

Walker, A. (2014). Towards a new science of ageing. In A. Walker (Ed.). The new science of ageing (pp. 1-23). Bristol: Policy Press.

Walker, A. (2015). Foreword. In K. Walsh, G. M. Carney, \& A. Ni Leime (Eds.). Ageing through austerity: Critical perspectives from Ireland (pp. vii-x). Bristol: Policy Press.

Walker, A., \& Walker, C. (1998). Normalisation and 'normal' ageing: The social construction of dependency among older people with learning difficulties. Disability \& Society, 13(1), 125-142.

Warmoth, K., Lang, I. A., Phoenix, C., Abraham, C., Andrew, M. K., Hubbard, R. E., \& Tarrant, M. (2016). 'Thinking you're old and frail': A qualitative study of frailty in older adults. Ageing and Society, 36(7), 1483-1500.

Woolham, J., Daly, G., Sparks, T., Ritters, K., \& Steils, N. (2017). Do direct payments improve outcomes for older people who receive social care? Differences in outcome between people aged $75+$ who have a managed personal budget or a direct payment. Ageing and Society, 37(5), 961-984. http://dx.doi.org/10.1017/ S0144686X15001531.

Working Group Report (2012). New directions: Review of HSE day services and implementation plan 2012-2016. Personal support services for adults with disabilities. Dublin: Health Service Executive.

World Health Organization (2002). Towards a common language for functioning, disability and health. The international classification of functioning, disability and health. Geneva: World Health Organization.

World Health Organization, \& The World Bank (2011). World report on disability. Geneva: World Health Organization.

Zarb, G. (2013). Personalisation and independent living. Spectrum Newsletter, October 2013Spectrum. Retrieved 3 January 2017 https://www.disabilityrightsuk.org/news / 2013/november/personalisation-now-independent-living-lite. 